\title{
Liquid Cell Transmission Electron Microscopy Reveals the Role of Nano-silica in Cement Hydration Reactions
}

Peng Dong ${ }^{1}$, Ali Allahverdi ${ }^{2}$, Carmen Andrei ${ }^{1}$ and Nabil Basim ${ }^{1}$

${ }^{1}$ McMaster University, Hamilton, Ontario, Canada, ${ }^{2}$ Iran University of Science and Technology, Narmak, Tehran, Iran

With the development of nanofabrication technology, liquid cell transmission electron microscopy (LCTEM) has gained much attention. The emerging technique allows new capabilities in realizing liquidphase chemical reactions within the traditional TEM and taking advantage of high spatial and energy resolution [1]. Ordinary Portland cement (OPC) and its concrete are the world's most widely used construction materials. The cement hydration reactions are very complicated due to multiple components in the reactants and products and the interactions between different reactions [2]. Cement hydration reactions are usually divided into early and late stages in terms of concrete life span, where the early-stage reactions are critically responsible for the development of strength and microstructure. Furthermore, many attempts have been conducted to add supplementary cementitious materials (SCM) to cement and concrete. One method is to substitute the use of OPC, whose production process requires a huge amount of energy and release enormous large quantities of $\mathrm{CO}_{2}$. The other way is to improve the hydration reactions by modifying the microstructure and hydration kinetics. The application of nano-silica in cement and concrete has attracted much attention. However, the role of nano-silica in cement hydration reactions needs to be clarified. Thus, a further understanding of the role of nano-silica in cement and concrete is crucial.

To meet conditions of electron-transparency, it was essential that cement particles be refined to nanoscale using ball milling. Nano cement was substituted by $1 \%$ nano-silica. A cement slurry of water to cement ratio of 15 was prepared with the presence of superplasticizer. The slurry was then sonicated for 5 min to effectively disperse nano-silica. The in-situ hydration reactions were performed using a Protochips liquid cell holder and imaging was conducted in ThermoFisher-FEI Titan operated at $300 \mathrm{keV}$. The early-age hydration reactions were monitored over the span of $24 \mathrm{~h}$ and the morphology of main hydrated products was obtained.

The results show that $\mathrm{C}-\mathrm{S}-\mathrm{H}$ precipitates at $2 \mathrm{~h}$ on the $\mathrm{SiN}$ membrane (Fig. 1) were irregular in shape. Fig. 2 displays needle-like ettringite crystals that were precipitated in the very early hydration reactions $(2 \mathrm{~h}$ 20 min). Some ettringite crystals were surrounded by C-S-H precipitates. The fact that C-S-H grew along needle-like crystals shows the strong tendency of nano-silica to attach to ettringite and the role of nanosilica to provide increased nucleation sites for $\mathrm{C}-\mathrm{S}-\mathrm{H}$. This study confirms the formation of main hydrated products in cement slurry with the addition of nano-silica. The role of nano-silica on hydration products are further clarified by post-situ TEM and scanning electron microscopy (SEM) and energy dispersive spectroscopy (EDS). 


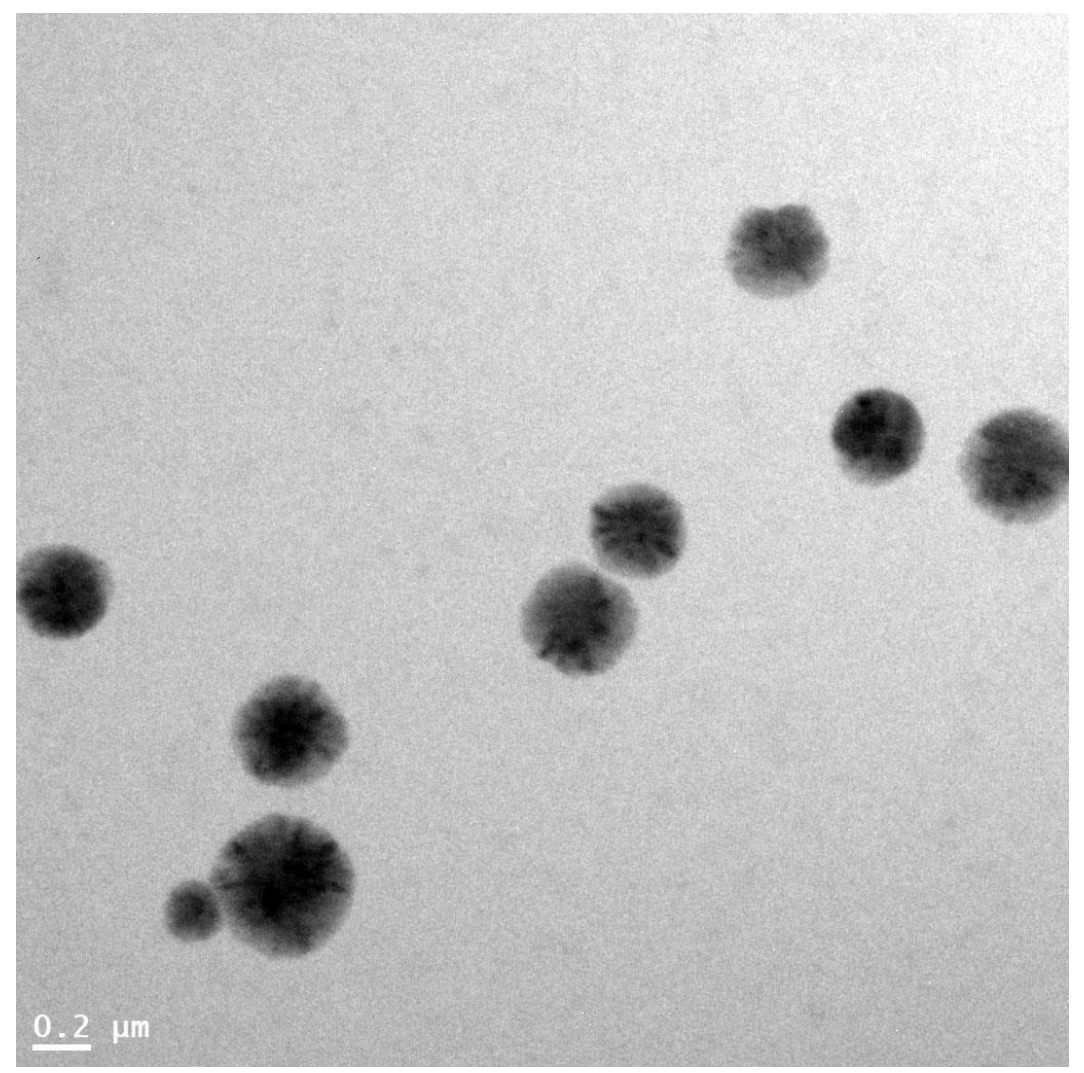

Figure 1. C-S-H formation in cement hydration reactions with the addition of nano-silica at $2 \mathrm{~h}$

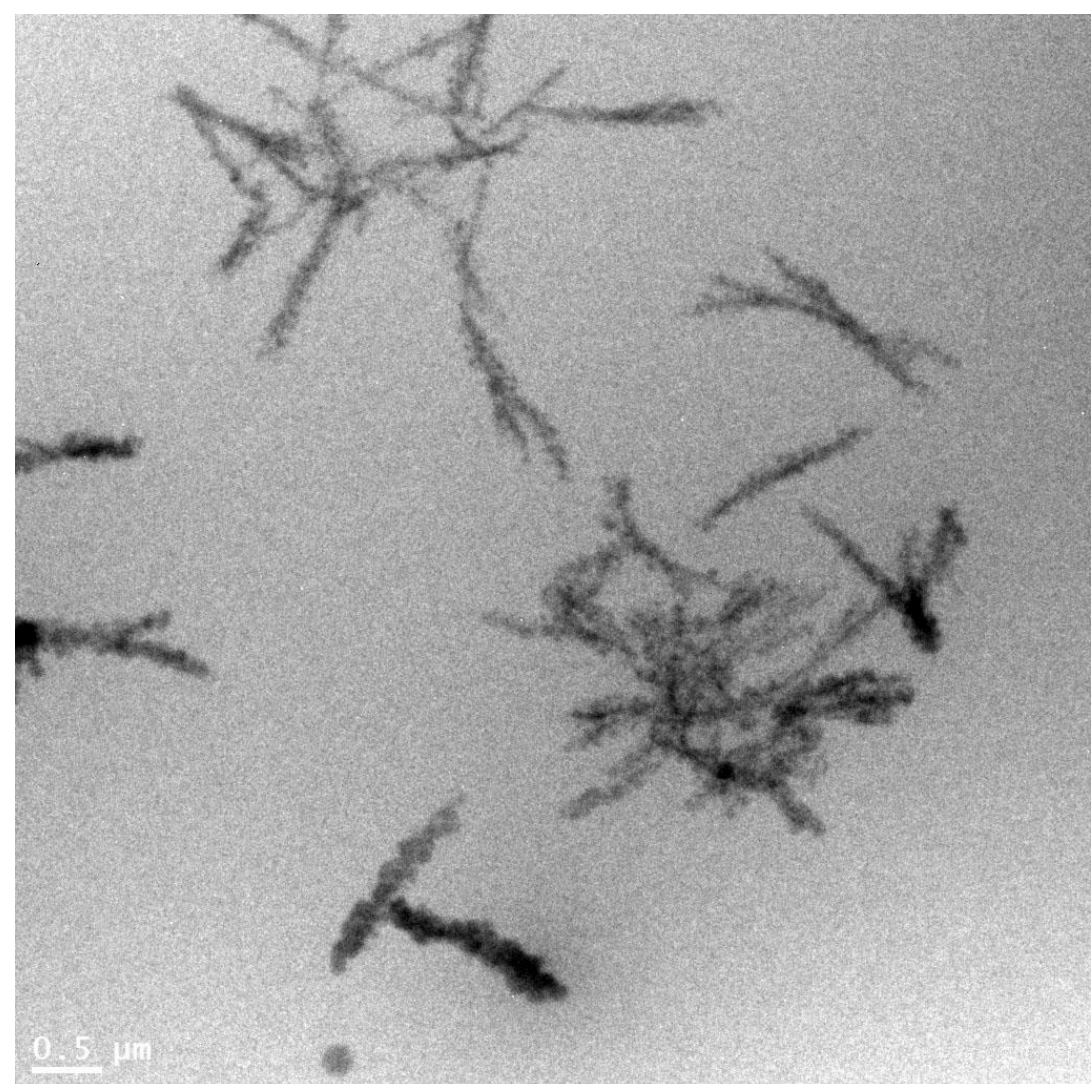

Figure 2. Ettringite formation in cement hydration reactions with the addition of nano-silica at $2 \mathrm{~h} 20 \mathrm{~min}$ 


\section{References}

1. Ross, F.M., Opportunities and challenges in liquid cell electron microscopy. Science, 2015. 350(6267): p. aaa9886.

2. Bullard, J.W., et al., Mechanisms of cement hydration. Cement and Concrete Research, 2011. 41(12): p. $1208-1223$. 